\title{
Kobe : the rise, fall and resurrection of an ocean city
}

\author{
John Piña Craven \\ Common Heritage Corp., Honolulu Hawaii
}

\section{I $\square$ INTRODUCTION}

There is nearly Universal agreement that the most pressing global problem of our time is the explosion in world population and its migration to the coastal zone. Cultural lag in the solution of global problems suggests that decades will pass before a global consensus will tailor the size of the human colony to match the environmentally sustainable resources of the earth. In the meantime progress toward a partial solution requires the development of design criteria for environmentally sustainable cities at the interface between land and sea.

Most of the senior participants in this conference have been dedicated to the resolution of this problem ever since the world's attention was released from the all consuming conduct of global war. But the nations of the world were still preoccupied with the deterrence of nuclear war and the cold and conventional wars associated therewith. Other peoples bathed in a local affluence, focused their attention on environmental preservation or on grandiose systems of science and space exploration.

But this was not altogether true. In the late sixties Arvid Pardo of Malta introduced the concept of The Common Heritage and the notion that the ocean could provide the resources for the sustenance of the common heritage. Architects and engineers rallied behind that principle to create the concepts and the technology that would give substance to Pardo's vision. In 1971, in pursuance of that vision the Architect Kikutake and the Ocean Systems engineer Craven collaborated on the design and test of a floating city concept as an environmentally sustainable solution to this formidable world problem.

Precursor to their design was the study of the evolution of sea based communities. In this they were aided and influenced by such people as Roger and Edith Rougerie whose global voyage documented the universal nature of the neolithic lake community as an organically developed community of humans in harmony with nature. From this evolved three design principles namely that an ideal city must ; 1) meet minimum requirements for the mechanics of living; b) provide protection against natural and man- made depredations or aversive stimuli, and provide ample opportunities for each individual to satisfy his or her genetically programmed needs for positive afferent reward. These criteria are in a sense the common heritage of the human species and in a metaphorical sense are identical with the inalienable rights of "life, liberty and the pursuit of happiness".

At the conclusion of the Hawaii floating city project, Kikutake and Craven (and others) sought ways to energize the body politic for the implementation of these concepts in an oceanic context [1]. At the same time they were students of the development of oceanic cities that seemed to be evolving in accordance with these principles. Most prominent of these cities was Kobe and although the direct involvement of Kikutake and Craven in the development of this remarkable community was minimal their involvement in the study of this development was intense. It seemed that its development was ideal with respect to these three fundamental criteria and that its evolution and growth into the twenty-first century would establish Kobe as the model for world wide replication.

\section{THE DEVELOPMENT OF KOBE}

Kobe's appearance in the evolution of Japan as a sea based society was not evident until after the Meiji restoration in 1867 and the world wide establishment of steam as the primary means of oceanic transport. Indeed the City of Kobe traces the origin of its port status to the opening of the port of Hyogo in 1868 [2]. But the seminal event for the genesis of Kobe as an evolutionary element in Japans relationship with the sea must have been the introduction of rail. The railroad must pass through Kobe if connectivity with Kyushu is to be established. Our first picture of Kobe in 1895 is dominated by the Western architecture of the railroad station. The establishment of this logistical root which will eventually develop into a high speed network for the rapid movement of people and goods along the spine of Japan and the development of motorized transport by sea now confers a comparative advantage to Kobe for

\begin{abstract}
Population explosion and coastal zone migration requires new designs for coastal cities. Kikutake \& Craven choose Kobe as a study of ideal ocean city. In its one hundred year evolution Kobe meets nearly all of the criteria for ideal coastal city; the mechanics of living, the avoidance of aversive stimuli and provision of opportunities for afferent reinforcement. The earthquake reveals design failure of fill islands. 1993 study of Kobe's future points to use of an inland sea "necklace" of floating and "soft landing" quasi floating complexes connected by marine mass transit as growth direction which will resurrect Kobe as the ideal ocean city.
\end{abstract}


movement of the industrial products of Japan into the worlds ocean and for import of the raw materials for this industrial revolution into quiet waters of the inland sea.

The realization of this heritage started after the SinoRussian war with the 1907 construction of the Shinko piers and expands after World War I with new Shinko, Naka and Hyogo piers. The latter were completed in 1939. The city was spared much of the destruction of World War II and was in a position to make a positive advance at the conclusion of the conflict.

The Kobe City Government became the Port Authority for Kobe in 1951. From that time the development of Kobe and its financing has been the result of a coherent planning process under the control and authority of the city fathers.

The author is not privy to the details of this process but the elements of a grand plan emerged in 1966 with the start of construction of the port island aptly named Portopia. This plan was revealed as the island was in construction and during operations prior to completion in 1981 .

\subsection{The port island}

Portopia is a fill island created with material from the far face of Koba mountain. The land scar which is thus produced has been replaced by a modern "new town" connected to the port by a funicular guideway. The periphery of the artificial island is largely reserved for container ship ports and terminals. An elevated highway and bridge system connects the island with the city and to the railroad network of Japan. Containers loaded in the most remote part of Japan are bar coded and begin their computerized automated journey by rail to the Portopia terminals where they are distributed to ships that will carry them to their overseas destination. The ships are designed to match the terminal facilities of Kobe and a sister port such as Seattle, Rotterdam or Tianjin China. Return cargoes are similarly programmed.

Automotive traffic enters the island over the same highway but is vectored into conduits leading to terminals or underground garages. The separation of vehicular traffic from pedestrian traffic is virtually complete. An automated rapid transit system is provided in a loop that provides convenient pedestrian access to every part of the island. The terminus of this system is the main train terminal in old Kobe from whence passengers can obtain quick access to all of Japan.

The centroid of the habitat for humans is the Portopia hotel. This facility provides the living spaces and accommodations for the needs of overnight visitors and the meeting rooms and conference centers for their intellectual pursuits. Within walking distance are high rise condominiums for full time residents of Portopia. Collocated with these condominiums are shops and department stores for food, clothing and amenities of life. A major terminal of the automated transport system is also collocated with this complex which integrates the population of greater Kobe with Portopia through convenient daily access. Kobe is thus clearly designed to meet the minimum requirements for the mechanics of living: i.e. an economic supply of water, food, clothing and sheiter for all the inhabitants, non-polluting, rapid comfortable flexible and immediate transportation for people who may be carrying 20 to $40 \mathrm{ki}$ lograms of goods, non-polluting and non-obstructive transportation of goods in quantities in excess of 80 pounds, telephone, radio, television, electronic mail, printed media, mail, accounting and computational communications, nonpolluting and efficient and effortless disposal of wastes human, solid, liquid, organic, toxic and non toxic.

It is in the provision of opportunities for positive reinforcement and in particular afferent reinforcement that Kobe and the port island stand out. Between the hotel and the contained port are a host of facilities designed for such reinforcement. A major amusement park provides the outlet for "thrill", for "release of aggression" and for laughter that is all too often achieved in other communities through speed on the highway, violence in the streets, and socially denigrating TV sitcoms. On the other side of the island are sport stadiums for baseball, for track and field and other athletic events where opportunities for communal thrill and release of tensions are frequent. Olympic size swimming pools on port island, the Marine Park on Rokko Island, the Rokko Mountain artificial ski slope, Suma beach swimming and wind surfing, tennis courts, and marinas for sailing boats all provide opportunities for participant athletics at a level which can release stress relieving endorphins, metabolize unhealthy fat, and provide aerobic conditioning for heart, lungs and limbs. Similar conditioning is provided by numerous, accessible hot springs [3].

Opportunities for aesthetic reinforcement abound. Port island has a world class fashion center. A design conference held in Kobe in 1982 demonstrated the role that design with a maritime flavor played in every functional and aesthetic facility in Kobe. The pedestrian mails in Portopia are in fact parks with numerous statues and art works of maritime flavor.

Opportunities to engage in traditional ceremony and religion abound in the many Temples in Kobe and nearby Kyoto and the many gardens where one can enjoy the tea ceremony. Many festivals associated with other Asian cultures Okinawan, Korean, Chinese, are complemented by many restaurants that serve specialized Asian cuisines.

What more can be said than that the city planners placed a high priority on the quality of life in the design of every aspect of the coastal city complex.

\subsection{What laks in Kobe}

How then can we speak of the fall of Kobe or that innovation would be required for its resurrection? The answer is found in the criteria for city design which relates to the avoidance of aversive stimuli. These include freedom from pollution - atmospheric, water, land, noise, and time pollution ; protection from fire, flood, tsunami, earthquake, hurricane, volcano and other natural disasters ; military defense, and protection against crime civil disorder and civil disaster, protection against illness, disease, epidemics and bodily injury ; provision of adequate public and private health and hospital facilities.

The record of Kobe with respect to most of these characteristics is excellent. One need only cite the excellent hospital facilities on Port Island. It is in the area of design for freedom from natural disaster that society in general has failed to take advantage of our new understandings of ocean technology. For example, the United States is but one nation facing the destructive power of hurricane and typhoon. Some twenty years ago its scientist explored ways in which, through seeding with silver iodide, the hurricane might be converted into a tropical storm. Initial success 
with both theory and experiment should have resulted in the development of a hurricane suppression capability of great value around the world. But innovation is the enemy of the status quo and it is the enemy of those who will derive economic income from alternate means of hurricane protection. Japan and Asia have made great strides in protection from typhoon damage. This has been achieved through modifications in the design of structure and in extensive port and harbor protection through breakwaters. Kobe is aided in this regard by the configuration of mountains and will not suffer from the disasters that have been visited and will be revisited upon U.S. East Coast and Gulf port cities. As the density of population increases in vulnerable areas the world will be forced to reexamine the technology of hurricane suppression, recognizing that its solution will obviate the need for expensive construction and reconstruction of its coastal cities.

The disaster that befell Kobe derived from its use of fill and the manner in which it was employed in construction of its water-front and port islands. This was a subset of the competition between fill and floating structures. The development of the semi-submersible with added mass resonant damping provided a platform that was decoupled from earthquake, immune from changes in sea level and tsunamis and highly resistant to hurricanes. Metaphorical enthusiasts quickly visualized these floating structures in terms of air fields.

\subsection{The airport}

The airport is a facility that requires a large surface area. Where a solid foundation is available the cost of runways is low. A floating structure is not efficient for use in structures which require large area and small volume but is very efficient for structures which require large volume and small area. When the airport is to be located in the coastal zone, the competition for area in or near the central city is intense.

If the water is shallow and the bottom is hard then the cost of competent fill will probably be much cheaper than the cost of volume for buoyancy. If the water is deep then the fill may cost more than buoyancy structure and the floating alternative becomes more attractive.

This dilemna was faced in the Kobe Osaka region when the Kansaï airport was first contemplated. Travelers will remember that it was far more convenient to take the bullet train from Osaka or Kobe to any destination in Tokyo than it was to take the long and onerous journey from the center of the city to Osaka airport, thence to Narita and finally, Tokyo. It is the authors understanding that the preliminary competition for the Kansaï airport was between a floating and a fill concept. The fill airport, the winner of the competition has since run into unanticipated subsidence problems. These problems can be handled from the standpoint of the airfield but may not with respect to the terminal. Designers and planners were wrestling with these long range problems when the earthquake struck Kobe.

As in the case of the hurricane, disaster proof design is, in part, dependent on the design of the specific structure and its ability to resist large dynamic loads and in part dependent on the reaction of the total environment to the forces of nature. In Kobe many, if not most of the new structures were designed to meet rigid earthquake stan- dards. Despite these designs, major damage occurred when large volumes of the fill islands were fluidized as a result of the earthquake.

This phenomenon does not occur in land fill unless the foundation is subject to artesional water. In the coastal zone, all fill structures are vulnerable to some degree. If piles are used, they will be effective if they are founded on solid rock. If however "set up" piles (i.e. piles that experience pile driver refusal after soil consolidation) then a strong earthquake will fluidize the bed and differential settling will topple the structure. An alternative to piles is the use of structures which literally float in the fill, as in Back Bay area of Boston. In the event of a partial fluidization of the bed, even such buildings may be subject to unacceptable tilt.

The failure of buildings is accompanied by the shearing of highways and pipe lines. Which in turn prevent the movement of fire engines and the delivery of water to quench the fires which are inevitably initiated. A map of Kobe showing the areas devastated by fire has an almost perfect correlation with distance from the waterfront. One can speculate that the very proximity of water provides a measure of insurance against the spread of fire when motorized pumpers are available.

The ability of external and internal community and the internal communities to respond immediately after is instructive. The most effective evacuation of people was by sea. Ships were not damaged even though the piers had been destroyed, and the ships ability to make up to a damaged pier is relatively easy. The number of passengers with valued belongings that can be carried is large. Photographs provided by the city of Kobe on the world wide web show a long line of people boarding a ship bound for Osaka on the day after the earthquake. A few days later the first cargo ship was able to unload its supplies in the port. The re-establishment of rail took longer because of the necessity of restoring track. Highways were jammed with evacuees and relief supplies.

\section{D AFTER THE EARTHQUAKE}

In the months following the earthquake the logistical system was once again functioning. Pictures of Port Island taken from the sea or of Kobe at night taken from the mountain are not easily distinguished from pictures taken before the earthquake. But the damage to the city which will take long to recover is the destruction of the lives, bodies, fortunes and spirit of the people of Kobe and the people with whom they relate. The loss of life during the earthquake was no less than that experienced in a major battle of a war. Habitats for the common man were easily destroyed and burned.

The author visited Kobe in the summer of 1995. His journey from Yokohama, a city unaffected by the earthquake, was swift and comfortable with no indication of the Kobe tragedy and travail. Overnight accommodations in a neighboring town were excellent. The train ride to Kobe was uneventful and the city terminal was fully operative. The first sights of buildings tilted and unoccupied were much less depressing than the sights of the many abandoned and condemned apartments in the poverty and drug abused "badlands" of New York City. In contrast to these wastelands the structures were isolates in a civilized me- 
tropolis. One was not able to get to Port Island without the use of bus on temporary roadway but it was possible. It was easy to walk from the station to Meriken Park, a more modern port and harbor complex as complement to Port Island. Again many structures such as the high rise Okura Hotel were intact and functioning. One could walk along the promenade of the Park and view a bustling harbor. One could step across the rifts in the roads created by the quake thus there was no part of the Park that was not accessible. But all of the afferent reinforcements were gone. The restaurants closed, the landscapes scarred, the highway silent, the strains of Mendelssohn's "Sadness of Soul" vibrated in the memory. The author and companion walked quietly to the Chinatown sector, a few blocks away. It was unscarred and a delightful lunch was available in a culturally reinforcing atmosphere but there was the realization that much had to be done in all areas of the city design to restore this remarkable city as the model for the many new coastal cities that must be built and most of all to restore the momentum that it had to continue its dynamic growth as a city of the sea.

But the seeds of resurrection had already been planted. In 1993 the City of Kobe was sponsor for the International Forum of Young Architects study of the future of coastal cities with Kobe as a model [4]. Kikutake was the Director of the Forum and Craven participated as juror and faculty. The participant studies were reinforcing and instructive. They strongly suggested the extension of Kobe into the sea with a "necklace" of floating and quasi floating complexes each featuring a major human function (health center, manufacturing, biotechnology, art and culture) etc. Much can be said for the "soft landing concept" for each of these complexes. This requires a continuous ballasting of each complex such that the stationary position is one of light pressure on the seabed to serve as anchor in the grounded configuration and a floating configuration for rotation and translation of the complex. In its totality this will result in a dynamic three dimensional galaxy with each complex optimized in its orientation and relationship with the environment. This will provide the opportunity for changing views and landscapes and seasonal position of seasonally associated functions (summer and winter sports, typhoons, climate changes). Gradually and over a period of years the city will become trimodal with its land based high density structures and new towns founded upon rock, with existing high density functions migrating out to sea and the central city being replaced with low density government, intellectual (Universities, museums, libraries) and biospheric facilities (temples, gardens, public parks, golf courses etc.) The main rail line would be the one between the mountain community, and the low lands ; the coastline, the divider between the lowlands and the habitats of the inland sea. The total human habitat will be connected by marine mass transit and light rail with numerous internodal transfer points. Then Kobe will be as it was, and is, and will always be the model for true Utopia of coastal cities in the best of all possible worlds.

\section{References}

[1] Craven J.P. (1980). - "Cities of the Future : The Maritime Dimension". How Big and Still Beautiful Westview Press pp. 178-205.

[2] Sasayama K. (1991). - Port of Kobe. Brochure City of Kobe.

[3] Sasayama K. (1992). - Kobe. Collection of Photographs City of Kobe.

[4] KikUtAKE K. et al. (1994). - IFYA KOBE 93. International Academy of Architecture Tokyo. 